\title{
ESTIMATIVA DO EFEITO DO USO E DA UMIDADE DO SOLO SOBRE A COMPACTAÇÃO ADICIONAL DE TRÊS LATOSSOLOS ${ }^{(1)}$
}

\author{
M. K. KONDO(2) \& M.S. DIAS J UNIOR ${ }^{(3)}$
}

\begin{abstract}
RESUMO
A compactação adicional do solo ocorre quando a pressão aplicada sobre ele é maior do que a pressão de preconsolidação, fazendo com que o solo se deforme ao longo da reta de compressão virgem. A reta de compressão virgem é a região onde ocorre a compactação adicional. Os objetivos deste estudo foram: testar o modelo proposto por Dias J unior (1994), propor um modelo para quantificar a resistência mecânica do solo e avaliar o efeito do uso do solo e da umidade na reta de compressão virgem e no índice de compressão de três Latossolos. Os solos sob as condições de uso com cultivo anual, mata natural e pastagem cultivada estão localizados na região de Lavras (MG). 0 trabalho foi executado durante os anos de 1996 e 1997. Para a condição de cultivo anual, mata natural e pastagem, foram coletadas cinco amostras indeformadas, com três repetições, nas profundidades de 0-0,03 e 0,27-0,30 m, e utilizadas no ensaio de compressão uniaxial. Coletou-se também uma amostra deformada, com três repetições em cada condição, para determinar o limite de plasticidade. Verificouse que, à medi da que o valor da umidade aumenta, as retas de compressão virgem são deslocadas para a região de menor pressão, o que indica aumento da suscetibilidade do solo à compactação, diminuindo, entretanto, a resistência mecânica a ser vencida pelo sistema radicular. Os índices de compressão não diferiram estatisticamente para o cultivo anual e mata natural na profundidade de 0-0,03 m, o que não ocorreu para a pastagem cultivada em ambas as profundidades e para o cultivo anual e mata natural na profundidade de 0,27-0,30 m. Nessas condições, a densidade do solo final e o índice de compressão do solo segui ram os modelos propostos por Dias J unior (1994). Em geral, os solos sob mata natural na camada de 0-0,03 $\mathrm{m}$ foram mais suscetíveis à compactação por apresentarem maiores valores do índice de compressão máximo.
\end{abstract}

Termos de indexação: compactação do solo, modelagem, Latossolo, curva de compressão, pressão de preconsolidação, índice de compressão, resi stência mecânica.

\footnotetext{
(1) Parte da Tese de Mestrado do primeiro autor, apresentada ao DCS/UFLA. Projeto financiado pelo CNPq. Recebido para publicação em agosto de 1998 e aprovado em setembro de 1999.

(2) Engenheiro-Agrônomo, MS, Pós-graduando do Departamento de Ciência do Solo, Universidade Federal de Lavras - UFLA. Caixa postal 37, CEP 37200-000 Lavras (MG). Bolsista da CAPES.

(3) Engenheiro Agrícola, Ph.D, Professor Adjunto IV do Departamento de Ciência do Solo, UFLA. Bolsista do CNPq.
} 


\title{
SUMMARY: ESTIMATE OF THE EFFECT OF SOIL MANAGEMENT AND MOISTURE CONTENT ON ADDITIONAL COMPACTION OF THREE LATOSOLS
}

\begin{abstract}
Additional soil compaction occurs when thepressureapplied on thesoil is greater than the preconsol idation pressure, causing thesoil to deform along the virgin compression line. The objectives of this study were to validate the model proposed by Dias J unior (1994); to proposea model to quantify soil mechanical resistance and; to evaluatethe effect of soil use and moistureon thevirgin compression lineand on the compression index of three Latosols under annual crop, natural forest and cultivated pasture, located in Lavras (MG). This study was conducted throughout 1996 and 1997. F or annual crop, natural forest and pasture, five undisturbed soil samples were used with three replications, at depths of 0-0.03 and 0.27-0.30 m. Samples wereanalyzed by a uni axi al compression test. Disturbed soil samples with threreplications under each condition were col lected to determinethepl asticity limit. As soil moistureincreased, the virgin compression lines were shifted to the regi on of small pressures, increasing soil compaction susceptibility. At the same time, the mechanical resistance to be overcome by the roots system decreased. The compression index did not differ for theannual crop and natural forest in thesurfacelayer, but differed for thecultivated pasture in both depths and for annual crop and natural forest in the 0.27-0.30 m depth. Final soil bulk density and compression index followed the Dias J uni or (1994) models. In general, the soils under natural forest in the 0-0.03 m layer were more susceptible to soil compaction due to their greater values of maximum compression index.
\end{abstract}

Index terms: soil compaction, modelling, Latosol, compression curves, preconsolidation pressure, compression index, mechanical resistance.

\section{INTRODUÇÃO}

As operações motomecanizadas realizadas sem o controle da umidade têm contribuído para aumentar a compactação adicional dos solos (Pedrotti \& Dias J unior, 1996). A compactação adicional do sol o ocorre, quando a pressão aplicada sobre eleémaior do quea pressão de preconsolidação (Dias J unior, 1994; Dias J unior \& Pierce, 1996), fazendo com que o sol o se deforme ao longo da reta decompressão virgem. SegundoDias J unior \& Pierce (1996), a pressão de preconsolidação pode ser entendida como sendo a maior pressão que o solo já suportou no passado, o que, em termos de agricultura, reflete o tipo de manejo utilizado. A pressão de preconsolidação é, portanto, o limite de pressão que o solo suporta antes que a compactação adicional ocorra (Lafond et al., 1992; Dias J unior, 1994; Dias J unior \& Pierce, 1996). A reta de compressão virgem é uma parte da curva de compressão do sol o e representa a região onde ocorre a compactação adicional (Dias J uni or \& Pierce, 1996; Kondo, 1998). É nesta região que o solo sofre a pressão pela primeira vez (Gupta et al., 1989), ocorrendo, conseqüentemente, a compactação.

O entendimento da compactaçãoadicional do solo é importante, porque ela pode causar uma redução da adsorção de nutrientes pelo sol o e, ou, redução de sua absorção pel as plantas, dificultando a infiltração e redistribuição de água eas trocas gasosas e, ainda, aumentando a resistência mecânica dos solos e restringindo o crescimento radicular (Smucker \& Erickson, 1989; Bicki \& Siemens, 1991; Lafond et al., 1992) com conseqüente redução na produtividade das culturas e aumento da erosão hídrica (Unger, 1996; Van den Akker, 1997).

Vários pesquisadores têm demonstrado o efeito da resistência mecânica do sol o sobre o crescimento radicular. Ela limita a profundidade efetiva do solo e a densidade do sistema radicular das plantas, implicando um desenvolvimento lento ou nul o devido à redução da velocidade de avanço das raízes (Allmaras et al., 1988; Raghavan et al., 1990). Essas restrições limitam a prol iferação do sistema radicular das culturas, reduzindo, conseqüentemente, o seu acesso à água e nutrientes (Raghavan et al., 1990).

A resistência mecânica é uma propriedade dosolo, podendo, entretanto, ser influenciada pel os processos de compactação ou de adensamento decorrentes do uso e manejo. Em ambos os casos, o maior ou menor grau de resistência mecânica do solo é influenciado pela umidade (Raney \& Edminster, 1961). Assim, a resistência mecânica do solo pode ser entendida como sendo a máxima pressão suportada pelo solo sem haver compactação excessiva. 
A resistência mecânica do solo pode restringir o desenvolvimento do sistema radicular (Gill, 1961; Hoffmann \& J ungk, 1995). Para desenvolver em poros de diâmetro menor do que o seu, a raiz tem de exercer uma pressão suficiente para alargar o diâmetro do poro (Hoffmann \& J ungk, 1995), vencendo, portanto, a resistência mecânica que encontra. Essa pressão tem de ser maior do que a pressão de preconsolidação do solo (Römkens \& Miller, 1971), causando, conseqüentemente, a compressão do sol o ao longo da reta de compressão virgem (L afond et al., 1992).

A condição para queocorra compactação adicional do solo ou crescimento das raízes vai depender da pressão de preconsolidação, a qual, é função da umidade (Dias J unior, 1994; Kondo, 1998) e da densidade do solo inicial. Assim, métodos baseados na teoria da mecânica dos solos poderiam contribuir para mel hor entendimento do comportamento físico do solo (Veenhof \& McBride, 1996), o que talvez melhorassea previsão do momento de ocorrência das deformações irreversíveis (Binger \& Wells, 1992; McNabb \& Boersma, 1996; Veenhof \& McBride, 1996). Portanto, um model o que considerea pressão depreconsolidação como um indicador da capacidade de suporte de carga dos solos e de sua resistência mecânica talvez possa fornecer melhor predição desses processos. Para que a predição seja cientificamente válida, é necessário que o modelo matemático empregado relacione as pressões exercidas ao solo pelas máquinas ou pela raiz com as deformações passíveis de ocorrer em função da umidade e do manejo do solo.

Os objetivos deste estudo foram: testar o modelo proposto por Dias J unior (1994), para estimar a compactação adicional do solo, propor um modelo, para quantificar a resistência mecânica do solo e avaliar o efeito do uso do sol o e da umidade nas retas de compressão virgem e nos índices de compressão de três Latossolos.

\section{MATERIAL E MÉTODOS}

No estudo, foram utilizados um Latossolo Vermel ho-Amarel o sob cultivo anual, localizado no muniápio del jaci, MG, esob mata natural e pastagem cultivada, localizadas no município de Lavras, MG: um Latossolo Roxoe um Latossolo Vermelho-E scuro, ambos sob cultivo anual, mata natural e pastagem cultivada, localizadas no município de Lavras, MG, durante os anos de 1996 e 1997. A seguir, é apresentado um histórico dos sol os amostrados:

\section{(a) Latossolo Vermelho-Amarelo}

- Cultivo anual: cultivo convencional há mais de dez anos, com uso de arado de disco, grade aradora e grade niveladora, com um único plantio anual, de soja ou milho, no mês de outubro, relevo suave ondulado, Iatitude 2109'38"S e Iongitude 44955'05'W Gr.

- Mata natural: Floresta Tropical Subcaducifólia, relevo suave ondulado, latitude 21013'33"S e longitude 44057'35'W Gr.

- Pastagem cultivada: plantio de braquiária (Brachiaria decumbens Stapf) há mais de cinco anos, com capacidade de suporte animal de 01 cabeça/ha, relevo suave ondulado, latitude 21이'33"S elongitude 4457'37"W Gr.

(b) Latossolo Roxo

- Cultivo anual: cultivo convencional há mais de dez anos, com uso de arado de disco, grade aradora e grade niveladora, com um único plantio anual, de milho ou soja, no mês de outubro, relevo suave ondulado, Iatitude 21013'42"S e Iongitude 44958'37'W Gr.

- Mata natural: Floresta Tropical Subperenifólia, relevo suave ondulado, latitude 21013'38"S e longitude 44058'18'W Gr.

- Pastagem cultivada: plantio de braquiária (Brachiaria decumbens Stapf) há mais de cinco anos, com capacidade de suporte animal de 01 cabeça/ha, relevo suave ondulado, latitude 21의3'50"S elongitude 44으'59"W Gr.

\section{(c) Latossolo Vermelho-Escuro}

- Cultivo anual: cultivo convencional há mais de dez anos, com uso de arado de disco, grade aradora e grade niveladora, com um único plantio anual, de milho ou sorgo, no mês de outubro, relevo suave ondulado, latitude 2111'31"S e Iongitude 4457'44'W Gr.

- Mata natural: Floresta Tropical Subperenifólia, relevo suave ondulado, latitude 21013'11"S e longitude 4457'57'W Gr.

Pastagem cultivada: plantio de braquiária (Brachiaria decumbens Stapf) há mais decinco anos, com capacidade de suporte animal de 01 cabeça/ha, relevo suave ondulado, latitude 21이'37"S e longitude 44957'57"W Gr.

As condições supradescritas foram utilizadas para testar os modelos propostos por Dias J unior (1994), os quais são da forma:

$$
D s_{\text {final }}=D s_{\sigma p}+m \log \left(\frac{\sigma_{\text {final }}}{\sigma_{p}}\right)
$$

em que $\mathrm{Ds}_{\text {final }}$ é a densidade do solo ao final da aplicação de uma pressão predeterminada ( $\mathrm{s}_{\text {final }}$ ), maior do que a pressão de preconsolidação $\left(\mathrm{s}_{\mathrm{p}}\right) ; \mathrm{Ds}_{\mathrm{\sigma p}}$ é a densidade do solo correspondente à pressão de preconsolidação; $m$ é o índice de compressão (inclinação da reta de compressão virgem);

$$
\mathrm{m}=\mathrm{a} \mathrm{U}^{2}+\mathrm{b} U+\mathrm{c}
$$

em que m é o índice de compressão; $a$, b e c são parâmetros ajustados eU a umi dade do solo. 
Para cada um dos solos e condições de uso estudadas foi realizada a amostragem em três pontos escolhidos aleatoriamente, nas profundidades de 0-0,03 e 0,27-0,30 m. Em cada profundidade, foram col etadas cinco repetições de amostras indeformadas, usando um anel volumétrico de 0,064 m de diâmetro por 0,0254 $\mathrm{m}$ de altura. Essas amostras foram utilizadas no ensaio de compressão uniaxial. Col etaram-se, também, três repetições de amostras deformadas, para cada solo, condição de uso e profundidade, as quais foram usadas na determinação do limite de plasticidade (Sowers, 1965). Na condição de cultivo anual, a amostragem dos solos foi realizada logo após a col heita.

O ensaio de compressão uniaxial foi realizado pelo método descrito por Bowles (1986) modificado por Dias J unior (1994), utilizando as amostras indeformadas. Para obter diferentes umidades gravimétricas em laboratório, saturaram-se, inicialmente, as amostras indeformadas, as quais foram secas ao ar até obter a umidade do solo variando entre 0,04 e 0,49 kg kg-1. Após a obtenção destas umi dades, as amostras de sol os indeformadas foram submeti das ao ensaio de compressão uniaxial, usando um consolidômetro da marca Boart Longyear, cuja aplicação das pressões foi feita pela utilização de ar comprimido. As pressões aplicadas em cada amostra obedeceram à seguinte seqüência: $25,50,100,200,400,800$ e $1.600 \mathrm{kPa}$, sendo cada uma aplicada até que $90 \%$ da deformação máxima fosse al cançada (Holtz \& Kovacs, 1981) e, somente a partir deste ponto, é que se aplicou nova pressão. A curva de compressão do sol o foi obtida, plotando-se a pressão aplicada no eixo das abscissas (escala logarítmica) versus a densidade do solo correspondentea cada pressão no eixo das ordenadas (escala decimal). As pressões de preconsolidação e os índices de compressão foram determinados a partir das curvas de compressão, de acordo com Dias J unior \& Pierce (1995). As retas de compressão virgem foram extraídas da curva de compressão do solo, plotando-se a pressão de preconsolidação e a pressão de 1.600 kPa no eixo das abscissas, em escala logarítmica, com suas densidades do sol o correspondentes no eixo das ordenadas, em escala decimal.

As análises de regressão foram realizadas, utilizando-se o software Sigma Plot 4.0 (J andel Scientific), e a comparação das regressões foi feita por meio do procedimento descrito em Snedecor \& Cochran (1989).

\section{RESULTADOSE DISCUSSÃO}

A curva de compressão do solo (Figura 1) foi usada no desenvol vimento do model o para avaliar a compactação adicional do solo (Dias J unior, 1994) e a resistência mecânica que deve ser vencida pelo sistema radicular.
O aumento do logaritmo das pressões aplicadas, para os cinconíveis deumidadeestudados, ocasionou um aumento da densidade do solo, tanto antes como depois da pressão de preconsol idação $\left(\sigma_{p}\right)$ (F igura 1$)$. O incremento dos val ores da densi dade do solo para as pressões menores do que a pressão de preconsolidação (curva de compressão secundária) foi menor do que o incremento dos referidos valores para pressões maiores do que a pressão de preconsolidação (reta de compressão virgem). Esse comportamento na curva de compressão secundária foi influenciado pelos níveis de pressão já aplicados ao solo no passado e pelos processos de secagem e umedecimento (Dias J unior \& Pierce, 1996), o que resultou em deformações pequenas e recuperáveis, não conduzivas à compactação adicional do solo. Assim, o aumento da resistência mecânica do solo ao longo da curva de compressão secundária foi devido à aplicação de pressões durante o uso do solo ou a processos de secagem e umedecimento.

Baseado nestefato, a resistência mecânica quea raiz tem de vencer para crescer éigual à pressão de preconsolidação (Römkens \& Miller, 1971), a qual varia com a umidade do solo (DiasJ unior \& Pierce, 1996) e com o estado atual de compactação. As pressões maiores do quea pressão de preconsolidação $\left(\sigma_{p}\right)$, causaram maior aumento da densidade do solo ao longo da reta de compressão virgem, para todos os níveis de umidade estudados, ocasionando, portanto, uma compactação adicional (Gupta et al., 1989; Lebert \& Horn, 1991), levando a valores de

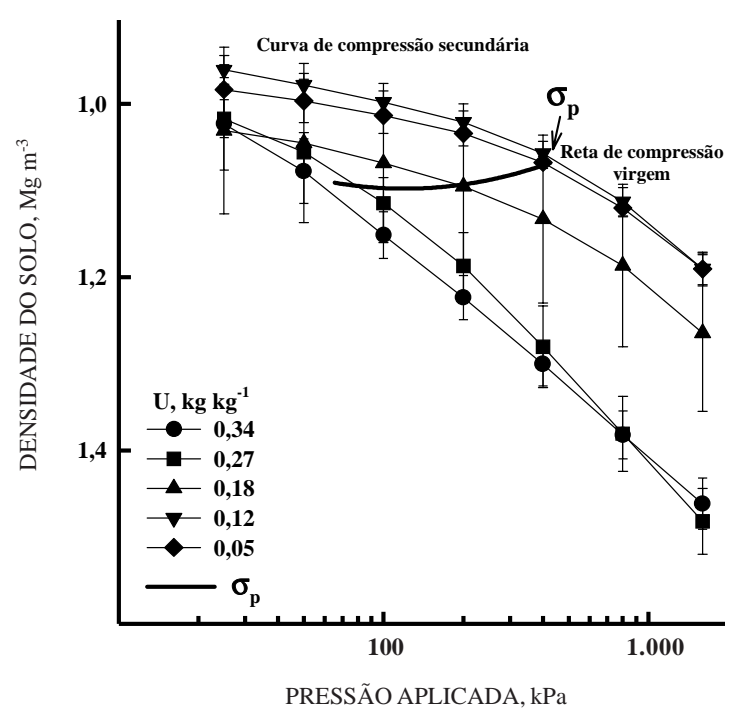

Figura 1. Curvas de compressão médias para o Latossolo Vermelho-Escuro sob cultivo anual, na profundidade de $0-0,03 \mathrm{~m}$, com diferentes umidades gravimétricas (U) (média de três repetições, sendo a barra de erro indicadora do desvio-padrão da média). 
densidade mais elevados para maiores níveis de umidade. Assim, solos previamente compactados podem restringir o crescimento radicular (Smucker \& Erickson, 1989; Lafond et al., 1992) com conseqüente redução na produtividade das culturas e aumento da erosão hídrica (Unger, 1996; Van den Akker, 1997).

A curva que representa a variação da pressão de preconsolidação com a umidade do solo constitui o model o para avaliar a resistência mecânica do solo a ser vencida pel o sistema radicular das plantas. Por outrolado, as retas de compressão virgem (Figura 2) constituem o modelo para avaliar a compactação adicional do solo causada pelas operações motomecanizadas ou pelo sistema radicular. Para pressões maiores do que a pressão de preconsol idação $\left(\sigma_{p}\right)$, os valores de densidade do solo aumentaram com o aumento do logaritmo das pressões aplicadas. I sto ocorreu mais acentuadamente para os maiores val ores de umidade, seguindo o model o proposto por Dias J unior (1994). Assim, à medida que o valor da umidade do solo aumentou, as retas de compressão virgem foram deslocadas para a região de menor pressão, o que significa um aumento da susceti bilidade do sol o à compactação, diminuindo, por outro lado, a resistência mecânica a ser vencida pelo sistema radicular das culturas.

Nas figuras 3, 4 e5, são apresentadas as retas de compressão para estimar as deformações irreversíveis (compactação adicional) para o Latossol o Vermel hoAmarelo, Latossolo Roxo e Latossolo Vermelho-

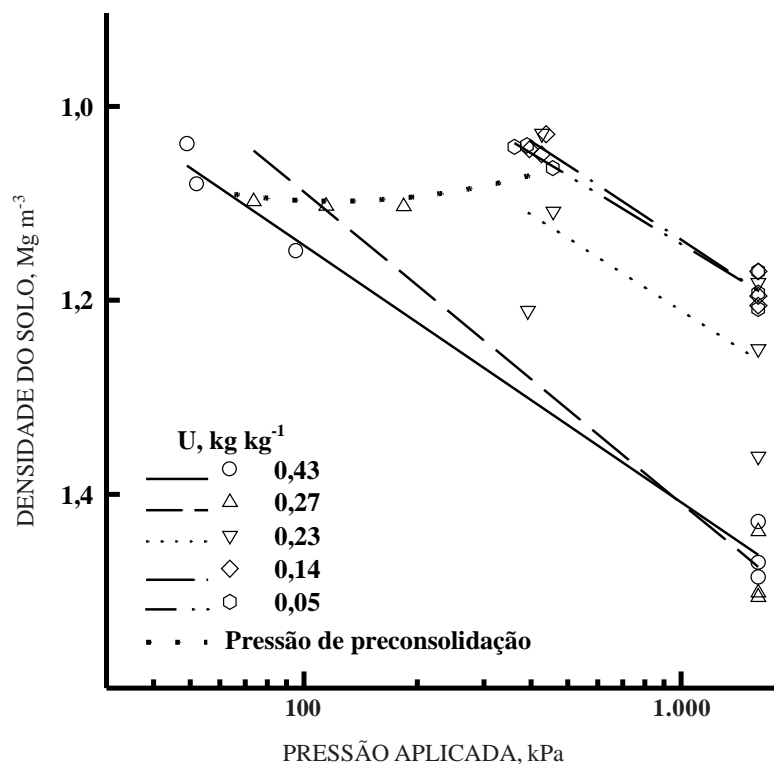

Figura 2. Retas de compressão virgem ajustadas para o Latossolo Vermelho-E scuro sob cultivo anual, na profundidade de $0-0,03 \mathrm{~m}$, com diferentes umidades gravimétricas $(U)(n=6)$.
Escuro, em duas profundidades, submetidos ao uso com cultivo anual, mata natural e pastagem cultivada. Para simplificar a discussão dos resultados, estes model os foram obtidos apenas para as condições de menor e maior umidade do solo durante os ensaios de compressão uniaxial .

Os índices decompressão das retas decompressão virgem para os três sol os na condição decultivo anual (Quadro 1 eF igura 3) não diferiram estatisticamente na profundidade de $0-0,03 \mathrm{~m}$. Na profundidade de 0,27-0,30 m, a condição mais seca no Latossol o Roxo e no Latossolo Vermelho-E scuro mostrou-se diferente da condição mais úmida do Latossolo Vermelho-Amarelo. Tal fatoé devido provavel mente à destruição da estrutura pelos implementos de preparo do sol o no uso com cultivo anual.

Os índices de compressão para a mata natural tiveram comportamento semelhante ao do cultivo anual na profundidade de 0-0,03 m (Quadro 1 e Figura 4). Na profundidade de 0,27-0,30 m, a condição mais seca no L atossolo Vermel ho-Amarel o foi diferente. Para a condição de pastagem cultivada (Quadro 1 e Figura 5), os índices de compressão foram estatisticamente diferentes para a condição mais seca e mais úmida, nas profundidades de 0-0,03 e 0,27-0,30 m, exceto para o Latossolo Vermelho-Amarelo na condição mais seca, mostrando o efeito da umidade na inclinação das retas de compressão virgem.

O Latossolo Roxo apresentou, em ambas as umidades estudadas, a maior resistência à deformação, nas duas profundidades, tanto para a mata natural quanto para a pastagem cultivada, o que pode ser visualizado pela reta de compressão virgem, situada acima das outras (Figuras 4 e 5). Esse aspecto está relacionado com sua microestrutura granular de alta estabilidade, conferida principalmente pelo seu maior teor de gibbsita (Ferreira, 1988). Quando mais úmidos, o Latossolo Vermel ho-Escuro e o Latossolo Vermelho-Amarelo apresentaram menor resistência à deformação para a condição de mata natural (Figura 4) e pastagem cultivada (Figura 5), respectivamente, conforme pode ser visualizado pelas retas de compressão virgem situadas abaixo das outras.

Pel o fato de as retas de compressão virgem para o cultivo anual não diferirem estatisticamente para os três tipos de solos, na profundidade de 0-0,03 e 0,27-0,30 m (Figura 3) pelo procedimento de comparação de regressões descrito em Snedecor \& Cochran (1989), as médias das pressões aplicadas e das densidades dos solos foram obtidas e plotadas, conforme mostra a figura 6 . Nesta figura, pode-se observar que a reta de compressão virgem, para a condi ção mais seca e mais úmida, estabelece olimite da região das deformações adicionais que poderiam ocorrer nestes solos sob cultivo anual, para estas umidades. Para umidades intermediárias àquelas 


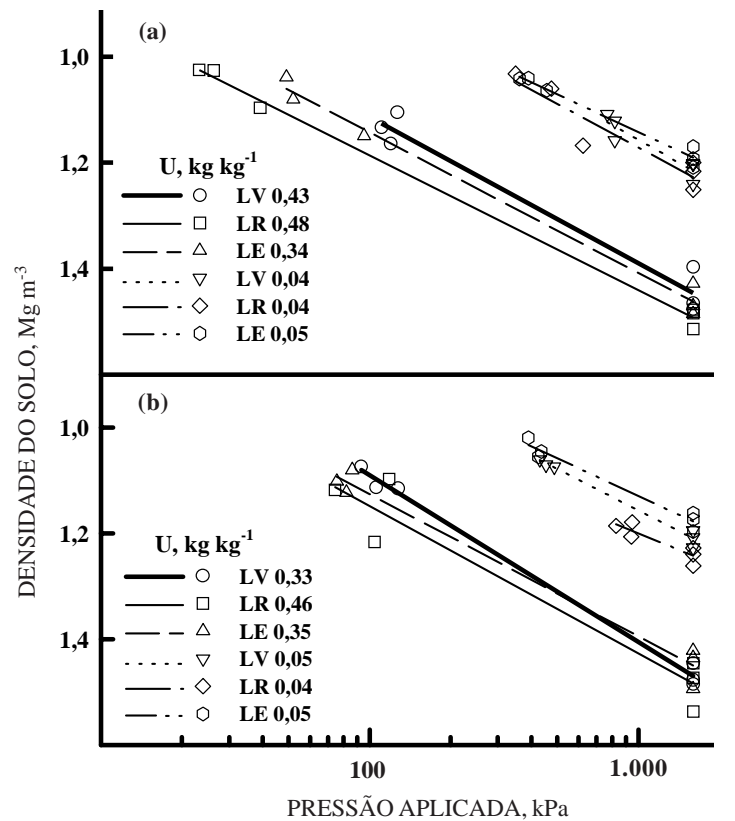

Figura 3. Retas de compressão virgem ajustadas para o Latossolo Vermelho-Amarelo (LV), Latossolo Roxo (LR) e Latossolo VermelhoEscuro (LE) sob cultivo anual, nas profundidades de 0-0,03 (a) e 0,27-0,30 m (b), com a maior e a menor umidade gravimétrica (U) utilizadas $(n=6)$.

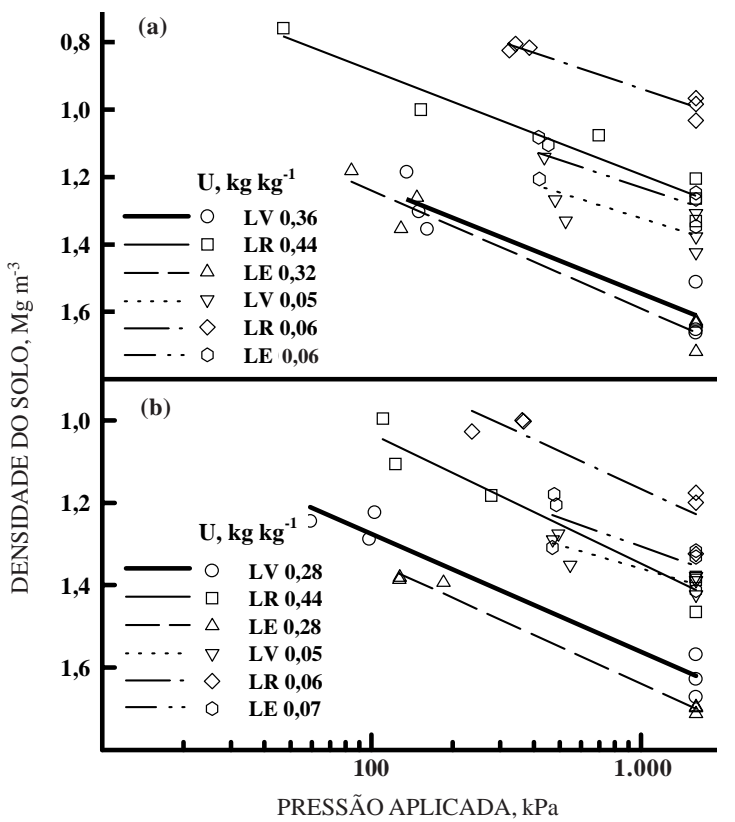

Figura 4. Retas de compressão virgem ajustadas para Latossolo Vermelho-Amarelo (LV), Latossolo Roxo (LR) e Latossolo VermelhoEscuro (LE) sob mata natural, nas profundidades de 0-0,03 (a) e 0,27-0,30 m (b), com a maior e a menor umidade gravimétrica (U) utilizadas $(\mathrm{n}=6)$.

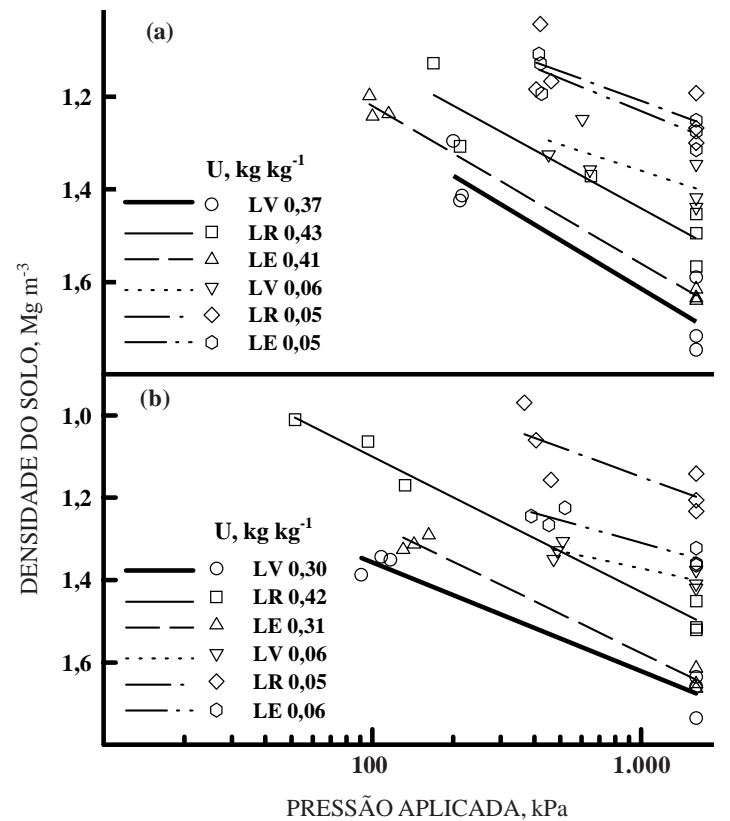

Figura 5. Retas de compressão virgem ajustadas para o Latossolo Vermelho-Amarelo (LV), Latossolo Roxo (LR) e Latossolo VermelhoEscuro (LE) sob pastagem cultivada, nas profundidades de 0-0,03 (a) e 0,27-0,30 m (b), com a maior e a menor umidade gravimétrica (U) utilizadas $(n=6)$.

estudadas neste trabalho, a estimativa das deformações adicionais do solo poderia ser feita por mei o da interpol ação de retas de compressão virgem entre as retas apresentadas na figura 6.

As figuras 7, 8 e 9 apresentam o índice de compressão pl otado versus a umi dade gravimétrica, para as condições deste estudo. Por meio destas figuras, obteve-se $m=f(U)$, conforme sugerido por Dias J unior (1994).

Os coeficientes de determinação $\left(R^{2}\right)$ variaram entre 0,14 e 0,80 (Figuras 7, 8 e 9). Apesar de algumas dessas relações apresentarem $R^{2}$ nãosignificativo, as equações de regressão entre a umidade e o índice de compressão do solo demonstraram que oíndice de compressão aumenta com o aumento da umidade até atingir o valor máximoe, a seguir, decresce. Comportamentosimilar também foi observado por Blackwell \& Soane (1981); Gupta et al. (1985); Reinert (1990); Dias J unior (1994); Kondo (1998). Tal fato podeser explicado pela analogia da mola (Holtz \& Kovacs, 1981), segundo a qual, quando uma pressão é aplicada ao solo seco, ela é suportada pel o solo e, à medida que a umidade aumenta, as deformações aumentam atéatingir um máximo e, a partir daí, decrescem com o aumento da umidade, pelo fato de ser, para alta umidade, parte da pressão aplicada dissi pada na água, reduzindo a 
Quadro 1. Índices de compressão (m) aplicados em cada nível de umidade sobre o Latossolo Vermelho-Amarelo (LV), Latossolo Roxo (LR) e Latossolo Vermelho-Escuro (LE), nas profundidades de 0-0,03 e 0,27-0,30 $\mathrm{m}(\mathrm{n}=3)$

\begin{tabular}{|c|c|c|}
\hline Solo & Umidade & $\mathbf{m}^{(1)}$ \\
\hline & $\mathrm{kg} \mathrm{kg}^{-1}$ & $\mathrm{Mg} \mathrm{m}^{-3}$ \\
\hline & \multicolumn{2}{|c|}{ Cultivo anual } \\
\hline & \multicolumn{2}{|c|}{$0-0,3 \mathrm{~m}$} \\
\hline LV & 0,43 & $0,28 \mathrm{a}$ \\
\hline LR & 0,48 & $0,27 a$ \\
\hline LE & 0,34 & $0,26 \mathrm{a}$ \\
\hline LV & 0,04 & $0,29 a$ \\
\hline LR & 0,04 & $0,25 a$ \\
\hline \multirow[t]{2}{*}{ LE } & 0,05 & $0,23 a$ \\
\hline & \multicolumn{2}{|c|}{$0,27-0,30 \mathrm{~m}$} \\
\hline LV & 0,33 & $0,32 \mathrm{a}$ \\
\hline LR & 0,46 & $0,28 a b$ \\
\hline LE & 0,35 & $0,27 a b$ \\
\hline LV & 0,05 & $0,26 a b$ \\
\hline LR & 0,05 & $0,21 b$ \\
\hline \multirow[t]{3}{*}{ LE } & 0,05 & $0,23 \mathrm{~b}$ \\
\hline & \multicolumn{2}{|c|}{ Mata natural } \\
\hline & \multicolumn{2}{|c|}{$0-0,03 \mathrm{~m}$} \\
\hline LV & 0,36 & $0,32 \mathrm{a}$ \\
\hline LR & 0,44 & $0,38 a$ \\
\hline LE & 0,32 & $0,35 a$ \\
\hline LV & 0,05 & $0,23 a$ \\
\hline LR & 0,06 & $0,27 a$ \\
\hline \multirow[t]{2}{*}{ LE } & 0,06 & $0,27 a$ \\
\hline & \multicolumn{2}{|c|}{$0,27-0,30 \mathrm{~m}$} \\
\hline LV & 0,28 & $0,29 a$ \\
\hline LR & 0,44 & $0,31 \mathrm{a}$ \\
\hline LE & 0,28 & $0,30 \mathrm{a}$ \\
\hline LV & 0,05 & $0,18 b$ \\
\hline LR & 0,06 & $0,31 \mathrm{a}$ \\
\hline \multirow[t]{3}{*}{ LE } & 0,07 & $0,23 a b$ \\
\hline & \multicolumn{2}{|c|}{ Pastagem cultivada } \\
\hline & \multicolumn{2}{|c|}{$0-0,03 \mathrm{~m}$} \\
\hline LV & 0,37 & $0,35 a$ \\
\hline LR & 0,43 & $0,31 \mathrm{a}$ \\
\hline LE & 0,32 & $0,34 a$ \\
\hline LV & 0,06 & $0,20 \mathrm{~b}$ \\
\hline LR & 0,05 & $0,21 \mathrm{~b}$ \\
\hline \multirow[t]{2}{*}{ LE } & 0,06 & $0,24 \mathrm{~b}$ \\
\hline & \multicolumn{2}{|c|}{ 0,27-0,30 m } \\
\hline LV & 0,30 & $0,27 a b$ \\
\hline LR & 0,42 & $0,33 \mathrm{a}$ \\
\hline LE & 0,28 & $0,32 \mathrm{a}$ \\
\hline LV & 0,06 & $0,14 \mathrm{c}$ \\
\hline LR & 0,05 & $0,22 b c$ \\
\hline LE & 0,07 & $0,19 \mathrm{bc}$ \\
\hline
\end{tabular}

(1) Letras iguais, dentro do mesmo uso e profundidade, não diferem estatisticamente entre si, a 5\%, pel o teste de Tukey.

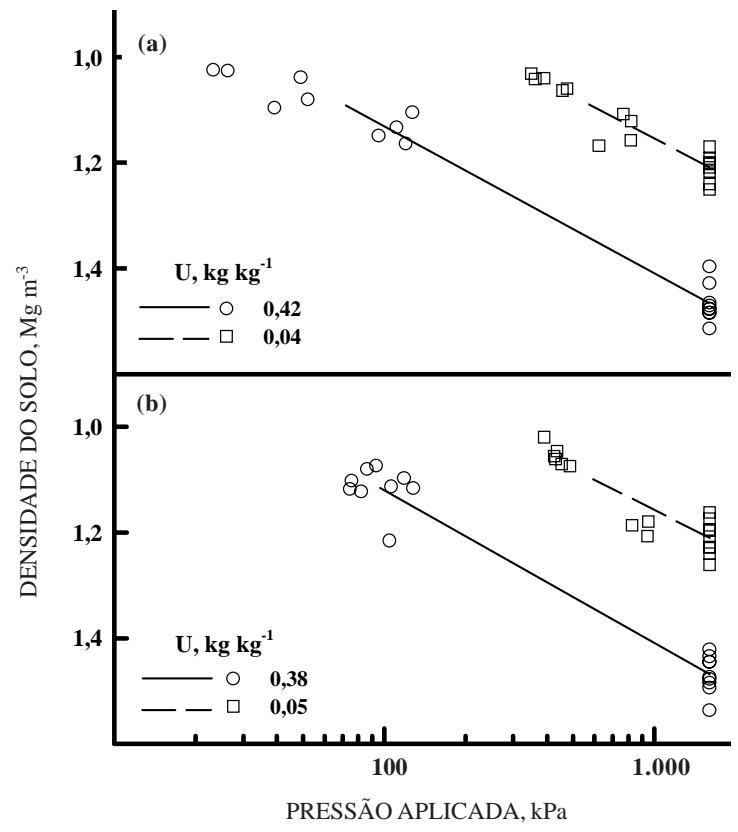

Figura 6. Retas de compressão virgem ajustadas para o Latossolo Vermelho-Amarelo, Latossolo Roxo e Latossolo Vermelho-Escurosob cultivo anual, nas profundidades de 0-0,03 (a) e 0,27$0,30 \mathrm{~m}$ (b), com a maior e a menor umidade gravimétrica $(U)$ utilizadas $(n=18)$.

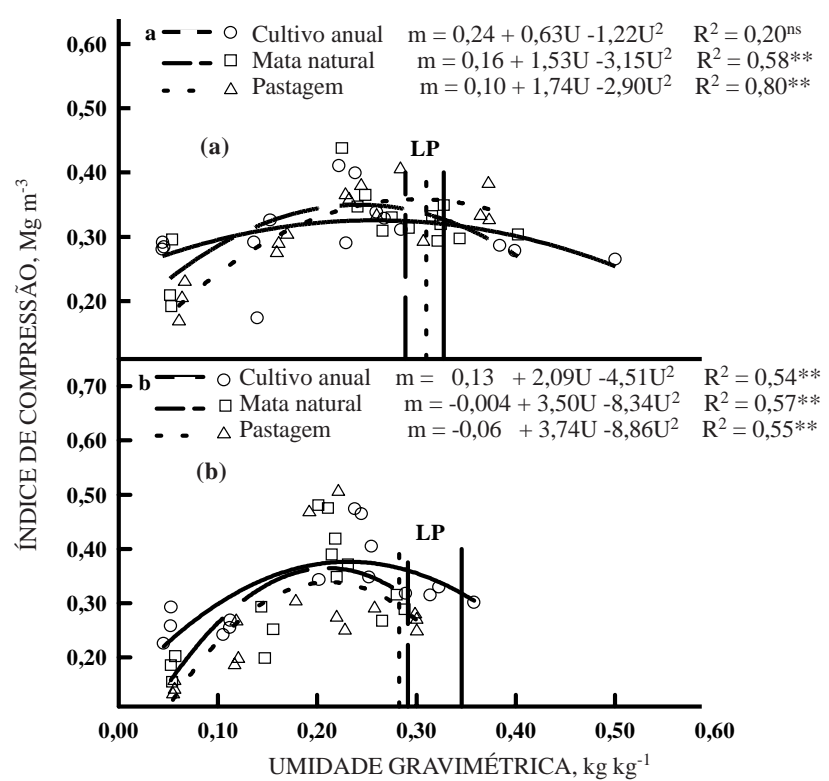

Figura 7. Relação entre a umidade gravimétrica (U) e o índice de compressão (m) para o Latossolo Vermelho-Amarelo, sob cultivo anual, mata natural e pastagem cultivada, nas profundidades de 0-0,03 (a) e 0,27-0,30 m (b), com 15 repetições (a linha vertical representa o limite de plasticidade (LP), com três repetições). $*, * *,{ }^{n s}$ significativos a 5 e $1 \%$ e não-significativo, respectivamente. 


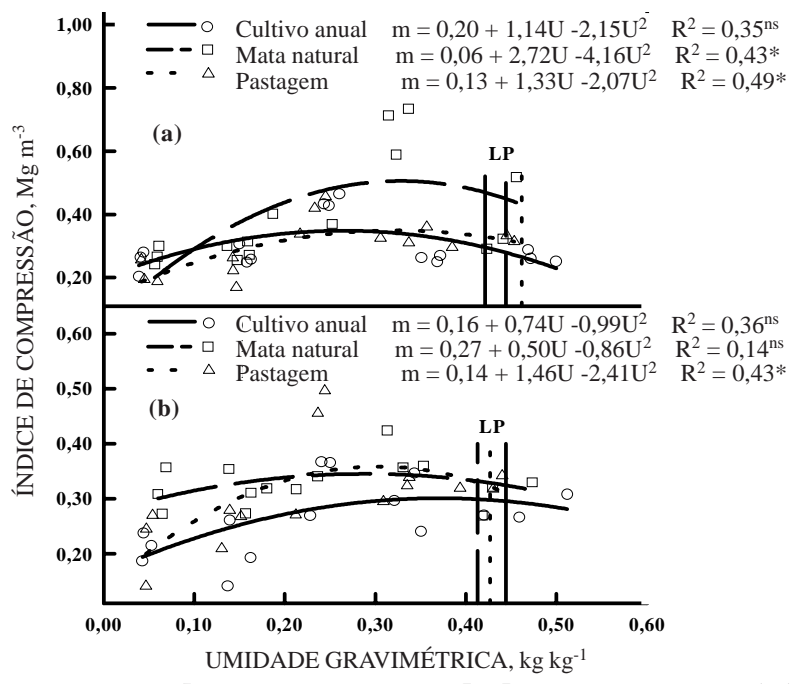

Figura 8. Relação entre a umidade gravi métrica (U) e o índice de compressão (m) para o Latossolo Roxo sob cultivo anual, mata natural e pastagem cultivada, nas profundidades de 0-0,03 (a) e 0,27-0,30 m (b), com 15 repetições (a linha vertical representa o limite de plasticidade (LP), com três repetições). *,**, ns significativos a 5 e $1 \%$ e não-significativo, respectivamente. pressão sobre o sol oe, conseqüentemente, sua deformação.

A camada superficial na condição de mata natural apresentou val ores de índice de compressão máximo $\left(m_{\text {máx }}\right)$ significativos para os três tipos de solos (Figuras 7, 8 e 9 e Quadro 2). Seus maiores valores podem evidenciar a maior suscetibilidade desta condição de uso do solo à compactação. Para a condição de cultivo anual, obtiveram-se menores valores do índice de compressão, apesar de nãosignificativos.J á para a profundidade de 0,27-0,30 m, esta tendência não foi verificada.

Em todas as condições de uso e tipos de solos estudados, os valores do limite de plasticidade foram mai ores do que a umidade no qual ocorre o $\mathrm{m}_{\text {máx }}$ (Quadro 2). O limitede plasticidadeéa umidade superior da faixa de friabilidade do sol o e, de acordo com a literatura, corresponde à faixa de umidade do solo em que as operações de preparo devem ser realizadas (Hillel, 1982). Tal fato pode ser umalerta a respeito do preparo do sol o na zona de friabilidade, sem levar em consideração os níveis de pressão por ele admissíveis, pois a compactação poderia estar ocorrendo dentro da zona de friabilidade do solo.

Quadro 2. Limites de plasticidade (LP), umidades máximas $\left(U_{\text {máx }}\right)$ e índices de compressão máximos estimados pelas equações desenvolvidas neste estudo $\left(m_{\text {máx }}\right)$ para o Latossolo Vermelho-Amarelo (LV), Latossolo Roxo (LR) e Latossolo Vermelho-Escuro (LE), nas profundidades de 0-0,03 e 0,27-0,30 m

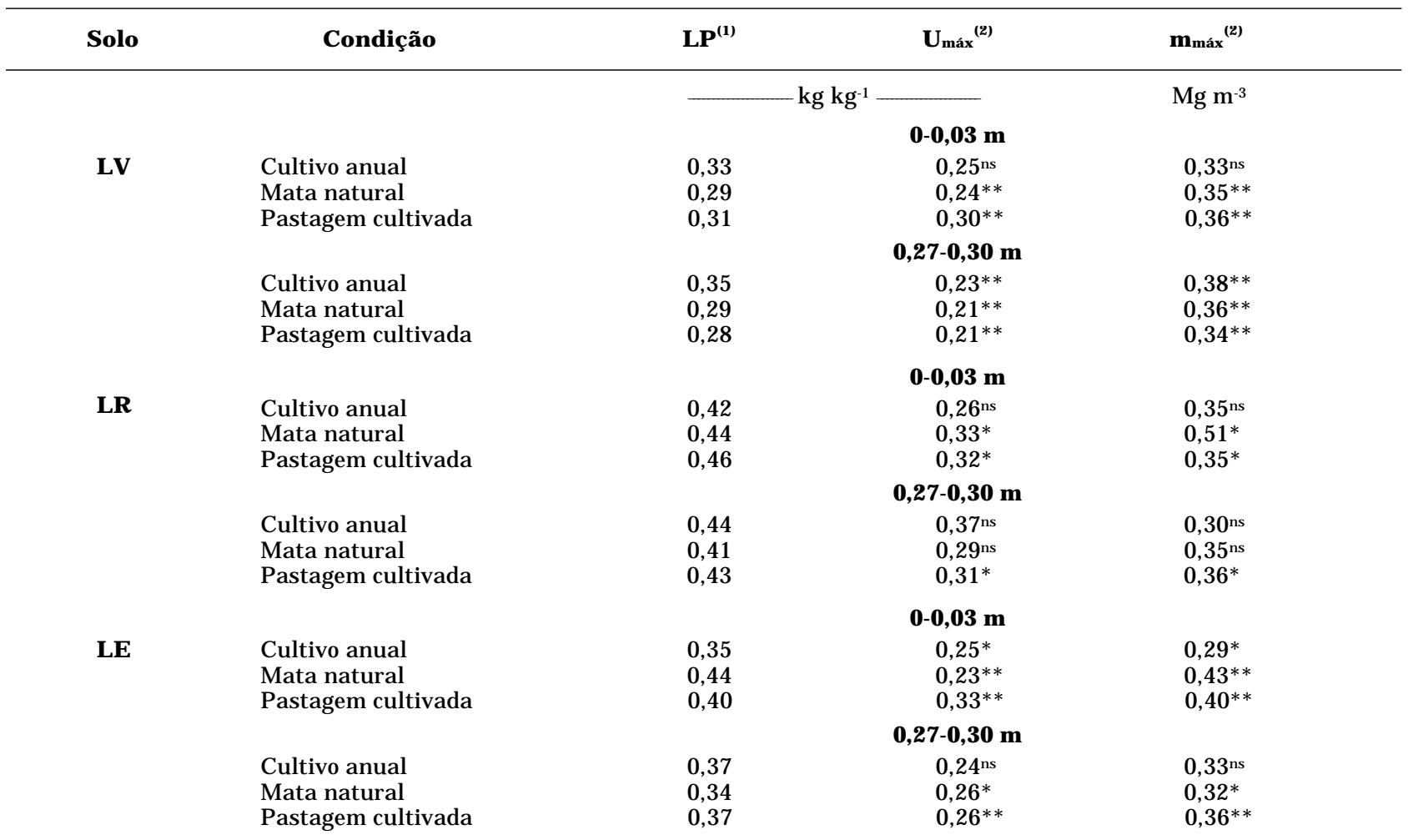

(1) Média de três repetições. (2) Estimado pelas equações desenvolvidas neste estudo e constantes nas figuras 7, 8 e 9. $*, * *,{ }^{n}$ significativos a 5 e $1 \%$ e não-significativo, respectivamente. 


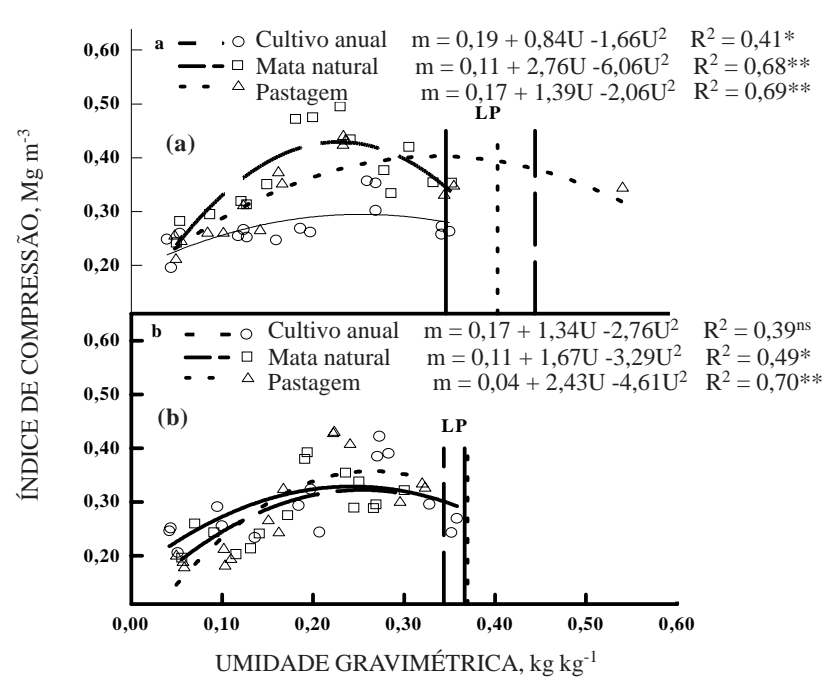

Figura 9. Relação entre a umidade gravimétrica (U) e o índice de compressão $(\mathrm{m})$ para o Latossolo Vermelho-E scuro, sob cultivo anual, mata natural e pastagem cultivada, nas profundidades de 0-0,03 (a) e 0,27-0,30 $\mathrm{m}$ (b), com 15 repetições (a linha vertical representa o limite de plasticidade (LP), com três repetições). $*$, **, ns significativosa 5 e1\%enão-significativo, respectivamente.

\section{CONCLUSÕES}

1. O modelo descrito por Dias J unior (1994) permite prever a compactação adicional dos solos estudados.

2. O modelo que permite prever a compactação adicional é o mesmo, para o Latossolo VermelhoAmarelo, Latossolo Roxo e Latossolo Vermel hoEscuro, quando submetidos ao cultivo anual. J á para a pastagem cultivada e mata natural, o model o teve comportamento distinto.

3. Para os solos e condições estudadas, à medida que a umidade do solo aumenta, as retas de compressão virgem são desl ocadas para a região de menor pressão, o que indica o aumento da susceti bilidade do sol o à compactação, diminuindo, entretanto, a resistência mecânica a ser vencida pelo sistema radicular das culturas.

\section{LITERATURA CITADA}

ALLMARAS, R.R.; KRAFT, J.M. \& SMUCKER, A.J .M. Soil compaction and crop residue management effects on root diseases of annual food legumes. In: SUMMERFIELD, R.J ., ed. World crops: cool season food legumes. Dordrecht, Kluwer Academic, 1988. p.627-647.

BICKI,T.J . \& SIEMENS, J .C. Crop response to wheel traffic soil compaction. Trans. Am. Soc. Agric. Eng., 34:909-913, 1991.
BINGER, R.L. \& WELLS, L.G. Compact - a reclamation soil compaction model. Part I. Model development. Trans. Am. Soc. Agric. Eng., 35:405-413, 1992.

BLACKWELL, P.S. \& SOANE, B.D. A method of predicting bulk density changes in field soils resulting from compaction by agricultural traffic. J. Soil Sci., 32:51-65, 1981.

BOWLES, J.E. Engineering properties of soils and their measurements. 3.ed. Auckland, McGraw-Hill, 1986.

DIAS J UNIOR, M.S. Compression of three soils under long-term tillage and wheel traffic. East Lansing, Michigan State University, 1994. 114p. (Tese de Doutorado)

DIAS JUNIOR, M.S. \& PIERCE, F.J. A simple procedure for estimating preconsolidation pressurefrom soil compression curves. Soil Technol., 8:139-151, 1995.

DIAS J UNIOR, M.S. \& PIERCE, F.J . O processo de compactação do sol o esua modelagem. R. Bras. Ci. Solo, 20:175-182, 1996.

FERREIRA, M.M. I nfluência da mineralogia da fração argila nas propriedades físicas de Latossolos brasileiros. Viçosa, Universidade Federal de Viçosa, 1988. 79p. (Tese de Doutorado)

GILL, W.R. Mechanical impedance of plants by compact soils. Trans. Am. Soc. Agric. Eng., 4:238-242, 1961

GUPTA, S.C.; HADAS, A. \& SCHAFER, R.L. Modeling soil mechanical behavior during compaction. In: LARSON, W.E.; BLAKE, G.R.; ALLMARAS, R.R.; VOORHEES, W.B. \& GUPTA, S.C., eds. Mechanics and related process in structured agricultural soils. Dordrecht, Kluwer Academic, 1989. p.137-152.

GUPTA, S.C.; HADAS, A.; VOOHEES, W.B.; WOLF, D.; LARSON, W.E. \& SCHNEIDER, E.C. Development of quids for estimating the ease of compaction of world soils. Bet Dagan, Israel, University of Minnesota, 1985. 178p. (Research Report, Binational Agric. Res. Development)

HOFFMANN, C. \& J UNGK, A. Growth and phosphorus supply of sugar beet as affected by soil compaction and water tension. Plant Soil, 176:15-25, 1995.

HILLEL, D. Introduction to soil physics. San Diego, Academic Press, 1982. 264p.

HOLTZ, R.D. \& KOVACS, W.D. An introduction to geotechnical engineering. Englewood Cliffs, Prentice-Hall, 1981. 733p.

KONDO, M.K. Compressibilidade detrês latossol os sob diferentes usos. Lavras, Universidade Federal de Lavras, 1998. 105p. (Tese de Mestrado)

LAFOND, J.;ANGERS, D.A. \& LAVERDIÈ RE, M.R. Compression characteristics of a clay soil as influenced by crops and sampling dates. Soil Till. Res., 22:233-241, 1992.

LEBERT, M. \& HORN, R. A method to predict the mechanical strength of agricultural soils. Soil Till. Res., 19:274-286, 1991.

MCNABB, D.H. \& BOERSMA, L. Nonlinear model for compressibility of partly saturated soils. Soil Sci. Soc. Am. J ., 60:333-341, 1996.

PEDROTTI, A. \& DIAS J UNIOR, M. S. Compactação do solo: como evitá-la. R. Agropec. Catarinense, 9:50-52, 1996. 
RAGHAVAN, G.S.V.; ALVO, P. \& MCKYES, E. Soil compaction in agriculture: a view toward managing the problem. Adv. Soil Sci., 11:1-36, 1990.

RANEY, W.A. \& EDMINSTER, T.W. Approaches to soil compaction research. Trans. Am. Soc. Agric. Eng., 4:246-248, 1961.

REINERT, D.J. Soil structural form and stability induced by tillage in a Typic Hapludalf. East Lansing, Michigan State University, 1990. 129p. (Tese de Doutorado)

RÖMKENS, M.J.M. \& MILLER, R.D. Predicting root size and frequency form one-dimensional consolidation data - a mathematical model. Plant Soil, 35:237-248, 1971.

SMUCKER, A.J .M. \& ERICKSON, A.E. Tillage and compactive modifications of gaseous flow and soil aeration. In: LARSON, W.E.;BLAKE, G.R.; ALLMARAS, R.R.; VOORHEES, W.B. \& GUPTA, S.C., eds. Mechanics and related processes in structured agricultural soils. NATO applied sciences. Dordrecht, Kluwer Academic, 1989. v.172. p.205-221.
SNEDECOR, G.W. \& COCHRAN, W.G. Statistical methods. Ames, I owa State University Press, 1989. 503p.

SOWERS, G.F. Consistency. In: BLACK, C.A., eds. Methods of soil analysis. Part 1. Madison, American Society of Agronomy, 1965. p.391-399. (Agronomy, 9)

UNGER, P.W. Soil bulk density, penetration resistance, and hydraulic conductivity under controlled traffic conditions. Soil Till. Res., 37:67-75, 1996.

Van den AKKER, J J J.H. Construction of a wheel-load bearing capacity map of the netherlands. In: BIBLIOTHECA FRAGMENTA AGRONOMICA - ISTRO CONFERENCE, 14., Pulawy, 1997. Proceedings. Pulawy, Polish Society of Agrotechnical Sciences, 1997. p.15-18.

VEENHOF, D.W. \& MCBRIDE, R.A. Overconsolidation in agricultural soils: I. Compression and consolidation behavior of remolded and structured soils. Soil Sci. Soc. Am. J ., 60:362-373, 1996 